\title{
COMPARATIVE EFFICACY OF TOPICAL CIPROFLOXACIN ON STAPHYLOCOCCUS AUREUS AND PSEUDOMONAS AUREGINOSA IN VITRO
}

BY

\author{
IKONNE*, E. U. AND ODOZOR, O. \\ DEPARTMENT OF OPTOMETRY, FACULTY OF HEALTH SCIENCES \\ ABIA STATE UNIVERSITY, UTURU. \\ EMAIL: drikonne@yahoo.com \\ *Corresponding author
}

\begin{abstract}
Tiprofloxacin is often considered drug offirst choice in the treatment of bacterial keratitis. Most of the ocular infections are caused by Staphylococcus aureus and Pseudomonas aeruginosa. This study set to compare the efficacy of ciprofloxacin on these two microorganisms in vitro. The "agar well diffusion" and the 10-fold serial dilution techniques were used respectively for the tests. Results of sensitivity test showed that P. aeruginosa had a higher mean zone of inhibition $(4.72 \mathrm{~cm})$ than $S$. aureus $(3.73 \mathrm{~cm})$, showing that ciprofloxacin is more efficacious against $P$. aeruginosa than against $S$. aureus. Ciprofloxacin is therefore recommended as drug of first choice in the treatment of ocular infections from Pseudomonas aeruginosa.
\end{abstract}

KEYWORDS: Ciprofloxacin, Pseudomonas aeruginosa, Staphylococcus aureus, bacterial keratitis.

\section{INTRODUCTION}

Germs or pathogens occur mostly as either bacteria or viruses. Others occur as fungi, protozoans or parasitic worms. These cause disease symptoms in a variety of ways. When these pathogens evade the host's tissue, they interfere with the normal functioning of the body and in some other cases; they destroy cells and tissues of the host's organ, the eye inclusive. There are different classes of the bacteria which include Staphylococcus aureus (S.aureus), Pseudomonas aeruginosa ( $P$. aeruginosa), Neisseria gonorrhoea, Streptococcus Pneumonia, Staphylococcus epidermidis, to mention but a few.

Staphylococcus aureus belongs to the group of bacteria called staphylococci, which are grampositive occurring in microscopic clusters resembling grapes ${ }^{1}$. The two distinguishable colony types are staphylococcus aureus (yellow) and staphylococcus albus (white). It forms fairly large yellow colony on rich medium and is often haemolytic on blood agar. It can grow in a temperature range of 15 to 45 degrees Celsius $\left(\left({ }^{\circ} \mathrm{C}\right)\right)$ and in Sodium chloride concentrations as high as $15 \%$. Almost all strains of $S$. aureus produce enzyme coagulase. S. aureus causes a variety of suppurative (pus-forming) infections and toxinoses in humans. It causes superficial skin lesions such as boils, styes, pneumonia, mastitis, meningitis, urinary tract infections and deep seated infections such as osteomyelitis and endocarditis ${ }^{2}$. The eye, an organ of sight is not spared by the pathogenicity of $S$. aureus. Some of the ocular diseases caused by $S$. aureus include simple bacterial keratitis, blepharitis, and orbital cellulities ${ }^{3}$.

Pseudomonas aeruginosa is a gram-negative aerobic rod belonging to the bacterial family pseudomonadaceae. The family includes other genera, which together with certain other organisms, constitute the bacteria informally known as pseudomonas. In the laboratory, the simplest medium for growth of $P$. aeruginosa consists of acetate for carbon and ammonium for nitrogen. The optimum temperature for growth is $37^{\circ} \mathrm{C}$ and it is able to grow at temperatures as high as $42^{\circ} \mathrm{C}$. It is resistant to high concentration of salts and dyes, weak antiseptic and many commonly used antibiotics. These natural properties of the bacterium, undoubtedly, contribute to its ecological success as an opportunistic pathogen ${ }^{4}$.

$P$. aeruginosa causes far reaching deleterious infection in the human eye. It is one of the most common causes of bacterial keratitis and has been isolated as the etiologic agent of neo-natal ophthalmia. Pseudomonas can colonize the ocular epithelium by means of a fimbrial attachment to sialic acid receptors. If the defenses of the environment are compromised in any way, the bacterium can proliferate rapidly and through the 
production of enzymes such as elastase, alkaline protease and exotoxin $\mathrm{A}$, cause a rapidly destructive infection that can lead to loss of the entire globe. $P$. aeruginosa is frequently resistant to many commonly used antibiotics. Although many strains are susceptible to gentamycin, tobramycin, amikin, and flouroquinolones resistant strains have developed ${ }^{4}$.

Ciprofloxacin is a class of antibiotics called flouroquinolones. It is used to treat some infections caused by bacteria. It is available in an aqueous $0.3 \%$ ophthalmic solution and is often considered drug of first choice for bacterial keratitis ${ }^{5}$. It has been shown to be successful in treating a corneal ulcer caused by methicillin resistant $S$. aureus and is reported to be more effective against $S$. aureus than are vancomycin and cefazolin ${ }^{6}$.

The objective of this study is derived from the fact that staphylococcal strains are developing a relatively high rate of clinical resistance against ciprofloxacin including the strains of Pseudomonas aeruginosa. Therefore, clinicians are confronted with choice of drug in their therapeutic regimen. Hence this study was set out to compare the sensitivity of $S$. aureus and $P$. aeruginosa to ciprofloxacin. It will also elicit which of the two that has the least minimum inhibitory concentration to ciprofloxacin.

\section{RESEARCH METHODOLOGY}

Eye swabs were collected from patients who visited the Abia State University Optometry Clinic. The swab stick was used to collect specimen from patients who had not used any antibiotic preparation. This was to ensure that the microbes were still in their active nature. These specimens were sent to the Microbiology laboratory of the University. The nutrient agar was prepared by adding $28 \mathrm{~g}$ of nutrient powder to 1 litre of deionised water and allowed to soak for 10 minutes ${ }^{2}$.

The mixture was stirred gently and sterilized by autoclaving at $121^{\circ} \mathrm{C}$ for 15 minutes. This was allowed to cool after which it was poured into plates and allowed to gel. The 'looping out' technique was used to inoculate the specimen because it helps to obtain a pure culture ${ }^{2}$. Furthermore, the microorganisms were subjected to gram staining to distinguish the type of bacteria as Gram positive and Gram negative species based on their decolourisation. For the S. aureus, a purple stain was observed, showing it as Gram positive bacteria, whereas a pink stain was observed for $P$. aeruginosa showing it as Gram negative bacteria ${ }^{7}$.

The organisms were stored in the refrigerator at $4^{\circ} \mathrm{C}$ after incubation at $37^{\circ} \mathrm{C}$ for $24 \mathrm{hrs}$. From the stored specimen, they were subcultured on nutrient agar plates and incubated overnight for reactivation of the organism for subsequent test.

The 10 fold serial dilution technique was used to dilute the topical ciprofloxacin in sterile water ${ }^{7}$. Twenty eight grams of nutrient powder was added to 1 litre of deionised water and allowed to soak for 10 minutes. The mixture was swirled gently and sterilized by autoclaving at $121^{\circ} \mathrm{C}$ for 15 minutes. It was allowed to cool after which it was poured into two different sterilized plates, about $3 \mathrm{~mm}$ in depth and allowed to gel. The 'spread plate technique" ${ }^{2}$ was employed to smear the $S$. aureus and $P$. auroginosa on the two gelled agar plates. Holes were bored in the plates using the cork borer $(5 \mathrm{~mm}$ in diameter). The different concentrations of the diluted ciprofloxacin were introduced, one drop each inside the holes. The drug was allowed to diffuse for 30mins in each of the plates, after which the plates were packed in the aluminum foil and sent for incubation at $37^{\circ} \mathrm{C}$ for $18 \mathrm{hrs}$.

After the duration of incubation, zones of inhibition by the different concentrations of the antibiotics were observed and recorded. The Agarwell diffusion method of Reeves ${ }^{2}$ was used to determine the zone size of inhibition of topical ciprofloxacin on the two organisms in question. The zones of inhibition were noted as the area where there was cessation of growth of the two micro-organisms. Using the millimetre rule, the areas of growth inhibition were measured and recorded.

\section{RESULTS}

Different dilutions of $0.3 \%$ ciprofloxacin were dropped on $P$. aureginosa and $S$. aureus respectively to determine their sensitivity to the drug.

Table 1 showed the serial dilution of $0.3 \%$ ciprofloxacin; from $3 \times 10^{-1} \mathrm{mg}$ concentration to $3 \times 10^{-5} \mathrm{mg}$ concentration. The zones of growth inhibition were measured along the vertical and 
horizontal meridian and the average recorded. Ciprofloxacin concentration of $3 \times 10^{-1}$ gave the highest zones of inhibition for the two microorganisms, $3 \times 10^{-5} \mathrm{mg}$ had noinhibitory effect on $P$. aeruginosa and concentration of $3 \times 10^{-4} \mathrm{mg}$ had no effect on $S$. aureus (see table 2). The sensitivity of $\mathrm{S}$. aureus and $\mathrm{P}$. aeruginosa was tested using two drops of $0.3 \%$ ciprofloxacin. The results showed that the microorganisms have the mean zones of inhibition of $3.73 \mathrm{~cm}$ and $4.72 \mathrm{~cm}$ respectively (see tables 4 and 5).

Tables and t-test at 0.01 level of significance were used to analyze results.

\section{DISCUSSION OF FINDINGS}

The minimum inhibitory concentration (MIC) of ciprofloxacin was determined using the 10-fold serial dilution method to ascertain the least concentration of the drug that will inhibit growth in $P$. aureginosa and $S$. aureus respectively. The concentrations of ciprofloxacin at different dilutions using the 10-fold serial dilution are found in Table 1. The results as tabulated in table 2 showed that the MIC of ciprofloxacin on $P$. aureginosa is $3 \times 10^{-4}$ with zone of inhibition of $1.75 \mathrm{~cm}$, while that for $S$. aureus is $3 \times 10^{-5} \mathrm{mg}$ with zone of inhibition of $1.70 \mathrm{~cm}$.

The results of the sensitivity test showed that $S$. aureus had a lesser mean zone of inhibition of
$3.73 \mathrm{~cm}$ while $P$. aeruginosa had a higher mean zone of inhibition of $4.72 \mathrm{~cm}$, showing that ciprofloxacin is more efficacious against $P$. aeruginosa than against $S$. aureus. This result is in agreement with the findings of past authors which showed that isolates of $P$. aeruginosa were susceptible to ciprofloxacin 5 . Jeffrey et $\mathrm{al}^{8}$ used ciprofloxacin for the therapy of experimental amino glycoside-resistant keratitis caused by $P$. aeruginosa; treatment with ciprofloxacin, applied topically, significantly reduced the number of viable bacteria.

Statistically, using the two-tailed T-test at 0.01 level of significance, $t_{\text {cal }}( \pm 9.90)$ lies outside $t_{\text {tab }}$ $( \pm 3.36)$ hence, ciprofloxacin was found to be more efficacious on $P$. aeruginosa than on $S$. aureus. From the results, it is safe to conclude that ciprofloxacin is more efficacious on P. aeruginosa than on $S$. aureus. It also means that $P$. aeruginosa has a lower MIC to ciprofloxacin than S. aureus.

It is also pertinent to note that this study was done in vitro outside the body immune system which may reduce the action of the antibiotics when applied in vivo. In spite of this observed limitation to the results of this study, it is recommended to eye care practitioners that topical ciprofloxacin should be drug of first choice in the management of ocular infections due to $P$. aeruginosa.

\section{REFERENCES}

1. Todar, K. (2004): Bacteria Resistance to Antibiotics. Todar's Online Textbook of Bacteriology. Sci. Mag. (304):1421-25.

2. Prescott L. M., John P. H. and Donald A. K. (2005) Microbiology, McGraw-Hill, pp896-7.

3. Synder M. E. and Kartz H. R. (1992): Ciprofloxacin-Resistant Bacterial Keratitis. Am. J. Ophthalmol, 114:336-8.

4. Vermon, M. O., Hayden M. K., Truck W. E., Hayes R. A. and Blom D. W. (2006): Antimicrobal Resistance Project. Arch. Int. Med, 166:306-12.

5. Leibowitz H. M. (1991): Antibacterial Effectiveness of Ciprofloxacin $0.3 \%$ Ophthalmic Solution in the Treatment of
Bacterial Conjunctivitis. Am. J. Ophthalmol, 112:29-33.

6. Brooks, K. C., Carroll, J. B. and Stephen, M. (2007): Jawezt, Melnick and Adelberg's Medical Microbiology. $24^{\text {th }}$ Edn. McGraw Hill Lange, 769pp.

7. Baron, E. J. O., Lance, R. P. and Sydney, M. F. (1994): Diagnostic Microbiology. $9^{\text {th }}$ Edn. The C. V. Mosby Company, 958pp.

8. Jeffrey, A. C., Michelle C., James M. H., Michael S. I. and Richard J. O., (1992): Topical Antibiotic Therapy for the treatment of experimental $S$. aureus Keratitis. Invest. Ophthalmol. Vis. Sci, 33(11): 3017-23. 
TABLE 1: DIFFERENT DILUTIONS OF 0.3\% CIPROFLOXACIN AND THEIR CONCENTRATIONS.

\begin{tabular}{|l|l|l|}
\hline Dilutions (ml) & Concentrations (g) & Concentrations (mg) \\
\hline $10^{-1}$ & $3 \times 10^{-4}$ & $3 \times 10^{-1}$ \\
$10^{-2}$ & $3 \times 10^{-6}$ & $3 \times 10^{-3}$ \\
$10^{-3}$ & $3 \times 10^{-8}$ & $3 \times 10^{-5}$ \\
$10^{-4}$ & $3 \times 10^{-10}$ & $3 \times 10^{-7}$ \\
$10^{-5}$ & $3 \times 10^{-12}$ & $3 \times 10^{-9}$ \\
\hline
\end{tabular}

TABLE 2: DIFFERENT DILUTIONS OF 0.3\% CIPROFLOXACIN AND THEIR RESPECTIVE AVERAGE ZONES OF GROWTH INHIBITION ON P. AERUGINOSA AND S. AUREUS

\begin{tabular}{|l|l|l|}
\hline & \multicolumn{2}{|c|}{ Zones of inhibition (cm) } \\
\hline Dilutions (ml) & P. Aeruginosa & S. Aureus \\
\hline $10^{-1}$ & 4.35 & 3.70 \\
$10^{-2}$ & 3.00 & 2.25 \\
$10^{-3}$ & 2.45 & 1.70 \\
$10^{-4}$ & 1.75 & - \\
$10^{-5}$ & - & - \\
\hline
\end{tabular}

TABLE 3:TWO DROPS OF 0.3\% CIPROFLOXACIN AND ZONES OF INHIBITION ON P. AERUGINOSA

\begin{tabular}{|l|l|l|l|l|}
\hline \multicolumn{2}{|c|}{} & \multicolumn{2}{|c|}{ Zones of inhibition (cm) } & \\
\hline Plates & Concentrations (g) & Vertical & Horizontal & Average (cm) \\
\hline 1 & 1.8 & 5.0 & 4.8 & 4.90 \\
2 & 1.8 & 4.7 & 4.8 & 4.75 \\
3 & 1.8 & 4.7 & 4.9 & 4.80 \\
4 & 1.8 & 4.7 & 4.5 & 4.60 \\
5 & 1.8 & 4.5 & 4.6 & 4.55 \\
\hline
\end{tabular}

TABLE 4: TWO DROPS OF CIPROFLOXACIN AND ZONES OF INHIBITION ON S. AUREUS

\begin{tabular}{|l|l|l|l|l|}
\hline \multicolumn{2}{|c|}{} & \multicolumn{2}{c|}{ Zones of inhibition (cm) } & \\
\hline Plates & Concentrations $(\mathbf{g})$ & Vertical & Horizontal & Average $(\mathbf{c m})$ \\
\hline 1 & 1.8 & 3.6 & 3.8 & 3.70 \\
2 & 1.8 & 3.7 & 3.9 & 3.80 \\
3 & 1.8 & 3.8 & 4.0 & 3.90 \\
4 & 1.8 & 3.5 & 3.7 & 3.60 \\
5 & 1.8 & 3.7 & 3.6 & 3.65 \\
\hline
\end{tabular}

